\title{
sciendo
}

\section{Efficacy Sources that Predict Leadership Behaviors in Coaches of Athletes with Disabilities}

\author{
by \\ Lawrence W. Judge', Stephen C. Woodward ${ }^{1}$, Andy D. Gillham ${ }^{2}$, Lindsey C. Blom ${ }^{1}$, \\ Donald L. Hoover', Makenzie A. Schoeff', Brian Fox ${ }^{1}$, Tammy Burt ${ }^{1}$, \\ David M. Bellar4
}

Researchers suggest that sport participation among athletes with disabilities promotes healthier lifestyles, increases self-esteem, and enhances peer acceptance. Ideally, coaches should be confident in teaching skills, tactics, and sportsmanship, while exhibiting appropriate leadership behaviors in order to positively impact the psychosocial development of any athlete. Thus, the present research examined sources of coaching efficacy that predict leadership behaviors in coaches who work with athletes who have physical disabilities. Seventy international Paralympic coaches of female and male sport teams completed a modified version of the Coaching Success Questionnaire-2, the Coaching Efficacy Scale and the Leadership Scale for Sports. Regression models indicated that total coaching efficacy was a significant predictor of instructional and positive feedback leadership behaviors, with prior success also being a significant predictor of instructional behavior.

Key words: coaching efficacy, disability sport, paralympic.

\section{Introduction}

\section{Athletes with Physical Disabilities}

Coaches serve as vital leaders in facilitating positive physical and psychosocial changes in athletes with physical disabilities (AWPD). Sport participation among athletes with disabilities promotes healthier lifestyles (Machek et al., 2008), increases self-esteem (Castagno, 2001), enhances peer acceptance (Gibbons and Bushkara, 1989), and boosts perceived competence (Gibbons and Bushkara, 1989). Developing ways to increase well-being in AWPD is especially important because researchers have shown that para-athletes have lower overall wellbeing, emotional regulation, self-acceptance, and motivation than able-bodied athletes (Macdougall et al., 2015, 2016). Thus, as a means of better facilitating positive attributes through sport participation, and reducing the negative ones, the coaching dynamic within sport for AWPD requires further comprehension.

Leadership Skills Addressing AWPD

One way to address specific needs of AWPD is through the development and demonstration of leadership behaviors. By developing such behaviors, coaches will be better able to facilitate change and foster successful outcomes for athletes. Coaching behaviors have been widely studied throughout the sport literature. Chelladurai and Saleh's (1980) model can be used to further frame leadership behavior into five aspects pertinent to sport coaches: instruction, democratic, autocratic, social support, and positive feedback. Other recent models of leadership applied to sport include transformational (Seltzer and Bass, 1990) and

1 - Ball State University, Muncie, USA.

2 - Sanford Sports Science Institute, Sioux Falls, USA.

3 - Western Michigan University, Kalamazoo, USA.

4 - University of North Carolina at Charlotte, Charlotte, USA. 
servant leadership (Greenleaf, 1977). Transformational leadership focuses primarily on helping athletes reach their potential through focusing on the vision and values of the team (Seltzer and Bass, 1990). Servant leadership (Greenleaf, 1977) refers to a leadership style that fosters a sense of community and teamwork through a process that involves others in the leader's decisions. This leadership style has been shown to be favored by competitors, leading to better outcomes and happier athletes (Rieke et al., 2008), while also demonstrating a high correlation with coaching success (Gillham et al., 2015).

Coaches in standing and wheelchair basketball (Robbins et al., 2010), elite rugby and cricket (Bennie and O'Conner, 2010), and elite soccer (Wang and Straub, 2012) self-reported a positive coaching leadership style with emphasis on learning, athlete development, and involvement. These studies demonstrate that not only is the coaching leadership style important, but top coaches report some common elements to their coaching approach. The soccer coaches reported developing an increasingly democratic approach to coaching that consisted of including athletes in decision-making (Wang and Straub, 2012). The rugby and cricket coaches (Bennie and O'Conner, 2010) reported viewing their athletes as unique individuals, fostering greater tolerance of their players' individual circumstances. Such findings are important in understanding types of leadership characteristics that promote relatedness, autonomy, and competence within and between athletes. Similar themes were found in the study utilizing individuals who coached both able-bodied athletes and AWPD (Robbins et al., 2010).

According to Castagno (2001), coaches of AWPD who were able to consider the special physical and psychological needs of their athletes reported increased verbal interactions with their players due to enhanced self-esteem, selfconfidence, and an expressed desire to make new friends. Similar to able-bodied athletes, AWPD tend to leave sport due to a loss of enjoyment or obligations that supersede athletics (Harada and Siperstein, 2009). For example, AWPD are likely to drop out because they no longer have access to sport programs due to life transitions, such as changes in school circumstances, graduation, and shifting to full-time employment. Essentially, if coaches are not making conscious efforts to implement effective leadership behaviors, AWPD are at risk for continued low well-being, dropping out, or other negative outcomes. One way for coaches to develop these leadership behaviors and other positive coaching characteristics is through increased coaching efficacy.

\section{Coaching Efficacy}

For coaches to be effective leaders, they must be confident in their abilities to positively influence the athletes' experiences. Introduced by Feltz et al. (1999), coaching efficacy is operationally defined as a coach's belief that he or she can stimulate an athlete's ability to learn and perform. More specifically, the concept of coaching efficacy is based on Bandura's (1986) portrayal of self-efficacy as a component of the social cognitive theory, which seeks to explain human motives, behaviors, and attitudes within the context of individual and environmental factors. Coaching efficacy was established as a multi-dimensional construct consisting of four main areas: game strategy, motivation, technique efficacy, and character building that influences the dynamic between the coach, athlete, and team (Feltz et al., 1999). Coaching behavior, athlete/team satisfaction, athlete/team performance, and athlete/team efficacy are primary outcomes of coaching efficacy (Feltz et al., 1999). Feltz and colleagues (1999) utilised a sample of 69 head high school basketball coaches and found that highly efficacious coaches displayed more frequent behaviors of praise and encouragement, while low efficacy coaches demonstrated more instructional and organizational behaviors. In the same sample, those authors also found that winning percentages and athlete satisfaction were significantly higher on teams coached by highly efficacious coaches. Total coaching efficacy has also been shown to predict coaching behavior, team winning percentage, and team satisfaction measures (Myers et al., 2005). Additional studies have established correlations between coaching efficacy and commitment to coaching (Kent and Sullivan, 2003), leadership styles (Sullivan and Kent, 2003), and team efficacy (Vargas-Tonsing et al., 2003).

Critical elements of successful coaching behavior are the demonstrated leadership attributes that arise from a leader's personal 
characteristics, including personality or ability factors (Chelladurai, 1999). These personal characteristics are notable in recent research on coaches of wheelchair and stand up basketball players (Robbins et al., 2010). That research revealed that effective coaches were concerned for the well-being of their athletes both on and off the court, emphasized effort in practice, exhibited flexibility, and recognized the need for personal coaching philosophy, regardless of the disability status of their athletes. Furthermore, the most effective coaches perceived the aforementioned personal characteristics within themselves to be more pertinent than the physical differences in their athletes. Such findings demonstrate the importance of coaching efficacy as a tool to develop coaching leadership, both in and out of sport for AWPD.

The limited research to date on the topic of coaching strategies and leadership behaviors in Paralympic coaches has hindered the understanding of the unique needs of AWPD. Therefore, the purpose of this exploratory study was to investigate how perceived coaching efficacy, sources of coaching efficacy, and types of leadership behaviors were related. Secondary purposes included: (1) the identification of which sub-scales of coaching efficacy predicted certain leadership behaviors, as well as (2) what sources of coaching efficacy predicted each type of leadership behaviors in Paralympic coaches of AWPD. Three primary research questions guided this study:

1. How are perceived coaching efficacy, sources of coaching efficacy, and types of leadership behaviors related?

2. Which subscales of coaching efficacy predict certain leadership behaviors?

3. What sources of coaching efficacy predict leadership behaviors in coaches of AWPD?

\section{Methods}

\section{Participants}

Permission to conduct the study was obtained from the authors' university Institutional Review Board before any data was collected, and participants' informed consent was electronically obtained in accordance with the Declaration of Helsinki. For this study current Paralympic coaches were defined as head or assistant coaches who were actively coaching Paralympic athletes at the time of instrument distribution. Paralympic coaches were utilized because of their involment in such an elite competition solely within sport for AWPD. A volunteer sample of 70 current international Paralympic coaches served as participants in this study (Table 1). The sample was majority male $(60 \%)$, Caucasian $(82.9 \%)$, and from the United States (87.1\%). All coaches had some experience with coaching both female and male teams, while thirteen coaches were identified as having a physical and/or intellectual disability. The age of the coaches sampled averaged 45.2 years old $(S D=11.7)$, with an average of 10.0 years $(S D=9.5)$ of coaching experience and 14.8 years $(S D=14.0)$ of playing experience. Twelve sports were represented, with the most prominent sport being Athletics/Track and Field $(52.9 \%)$, as well as alpine skiing, boccia, cycling, goalball, ice sledge hockey, rowing, swimming, volleyball, wheelchair basketball, wheelchair curling, and wheelchair tennis.

\section{Measures}

Multiple instruments were utilized to gather essential data necessary for this exploratory study with all variables across all instruments listed in Table 2. Information gathered included demographics (i.e., sex, age, country of origin, ethnicity, primary disability sport coached, sex of athletes coached, number of years coaching primarily disability sport, and number of years playing primary sport coached), sources of coaching efficacy, coaching efficacy level, and leadership behaviors.

\section{Sources of Coaching Efficacy}

Coaches' years of experience coaching their primary sport, as well as the years of experience playing their primary sport, were individually assessed on a ratio scale as part of the self-reported demographic responses. No instrument that adequately assessed coaches' perceptions of their own efficacy was found in one single form. To assess this concept, four subscales (i.e., enjoyment, skills and strategies, emotion management, and attitudes about winning) based on the Coaching Success Questionnaire (CSQ-2; Gillham et al., 2013) were utilized. These sub-scales were chosen because they most closely examined the variables of interest. The summation of each of the sub-scales provided the total coaching success score, which was used in this study to assess prior success. 
Each response was measured on a six-point Likert scale ranging from one (Strongly Disagree) to six (Strongly Agree).

Perceived athlete ability, perceived athlete improvement, and support variables were assessed with single-item questions developed by Feltz et al. (1999). These were measured on a 10point Likert scale ranging from zero (poor) to nine (excellent). Feltz et al. (1999) reported satisfactory test-retest reliability results from .80 to .89 using the aforementioned questions. These items were developed in conjunction with another instrument included in this study, i.e., the Coaching Efficacy Scale.

\section{Coaching Efficacy}

Developed by Feltz et al. (1999), the Coaching Efficacy Scale (CES) was employed to measure the coaches' level of efficacy. The CES consisted of 24 items and is separated into four subscales: game strategy (7 items), motivation (7 items), technique (6 items), and character building (4 items). Each item was rated on a 10-point Likert scale, ranging from zero (Not at all confident) to nine (Extremely confident). Analyses showed that each item was significantly related to one of the four factors being analyzed (Feltz et al., 1999). Acceptable reliability and test-retest values were present amongst the four factors: character building (.88 and .77), technique (.89 and .78), motivation (.91 and .83), and strategy (.88 and .84). The coefficient alpha for the total CES was evaluated at .95 and the test-retest coefficient was .82. The CES has been generalized widely, further supporting the reliability and validity to coaches in the United States (Myers et al., 2005) and university coaches (Kent and Sullivan, 2003; Sullivan and Kent, 2003). The four factors of coaching efficacy were all intercorrelated in the analysis of coaching efficacy as a predictor of university coaches' committment (Kent and Sullivan, 2003), which is consistent with previous research (Feltz et al., 1999). All factors showed acceptable internal reliability with Cronhbach's alpha of (.90) for motivational efficacy, (.87) for strategy, (.87) for character building, and (.82) for teaching technique. The orignal CES was selected for this study due to its more lengthy documented history of psychometric support and limitations.

\section{Leadership Behaviors}

Leadership behaviors were assessed using the Leadership Scale for Sport (LSS)
(Chelladurai and Saleh, 1978). The original version of the LSS was chosen for use in this study, as the revised LSS was substantially longer and has not demonstrated substantially better psychometric properties (Chelladurai, 2007; Walach-Bista, 2014). The LSS contains five important aspects of leadership behaviors: instruction, democratic, autocratic, social support, and positive feedback. Instruction referred to the behavior intended to improve athletes' performance by teaching skills and directing training activities. The self-report questionnaire was comprised of 40 items which were evaluated on a five-point scale ranging from one (Always) to five (Never).

\section{Design and Procedures}

Data collection occurred in the eight months prior to the summer 2012 Paralympic Games in London, England. A purposive sample of Paralympic coaches were recruited to participate in this study 1) through an e-mail by the High Performance Director of USA Paralympic Track and Field, 2) through an e-mail by the first author to organizations listed on the United States Paralympics Sports Club website, and 3) by the distribution of flyers at the 2012 BT Paralympic World Cup in Manchester, England. Information about the study was provided to the coaches with a hyperlink to an online survey software program (SurveyMonkey, San Mateo, CA, USA) that included the study details. The link provided information on the purpose of the study, informed consent, guarantee of response anonymity and confidentiality, and the questionnaires.

Statisitcal Analysis

Statistical analysis was performed using the Statistical Package for the Social Sciences, v21.0 (IBM, Armonk, NY, USA). Pearson correlations were used to analyze the relationship among measures of perceived coaching efficacy, sources of coaching efficacy, and types of leadership behaviors. Hierarchical multiple regression analyses were employed to examine the sources of coaching efficacy that predicted leadership behaviors in coaches of AWPD. The criterion variable was total coaching efficacy level, as determined by the summation of each sub-scale of the CES. The predictor variables, which combined interval and ratio scales, consisted of the sources of coaching efficacy, i.e., coaching 
experience, playing experience, prior success, athlete ability, athlete improvement, athlete support, community support, and organizational support. The level of significance was set at $p \leq$ 0.05 .

\section{Results}

\section{Relationship between Coaching Efficacy, Sources, and Leadership Behaviors}

It was hypothesized that coaching efficacy should be positively correlated with each source of coaching efficacy, positive feedback leadership behaviors, and instructional leadership behaviors. In general, results conformed to support Hypothesis one. See Table 2 for full listing. Each source of coaching efficacy was significantly correlated with the total coaching efficacy level. There was a relationship between the total coaching efficacy level and democratic, instructional, and positive feedback leadership behaviors. There were smaller values on the LSS implying more positive perceptions of leadership behavior, thus negative correlations indicated positive relationships. Significant relationships were also found between various sources of coaching efficacy and certain dimensions of leadership behavior. Explicitly, instructional leadership behavior was significantly related to playing experience, prior success, athlete performance, athlete improvement, and athlete support. Democratic behavior was significantly correlated with community support, while social support behavior was significantly correlated with prior success.

\section{Coaching Efficacy Sub-scales that Predict Leadership Behaviors}

Multiple regression models were utilized to predict which subscales of coaching efficacy would predict each type of leadership behavior (Table 3). As a group, the sub-scales of coaching efficacy accounted for $50.0 \%$ of the variance in instructional behavior, $F(4,65)=16.27, p<.05$, with the technique efficacy subscale as the only significant individual predictor. For positive feedback, $20.2 \%$ of the variation was accounted for by the group of coaching efficacy subscales, $F$ $(4,65)=4.13, p<.05$, with no individual coaching efficacy subscales as significant predictors.

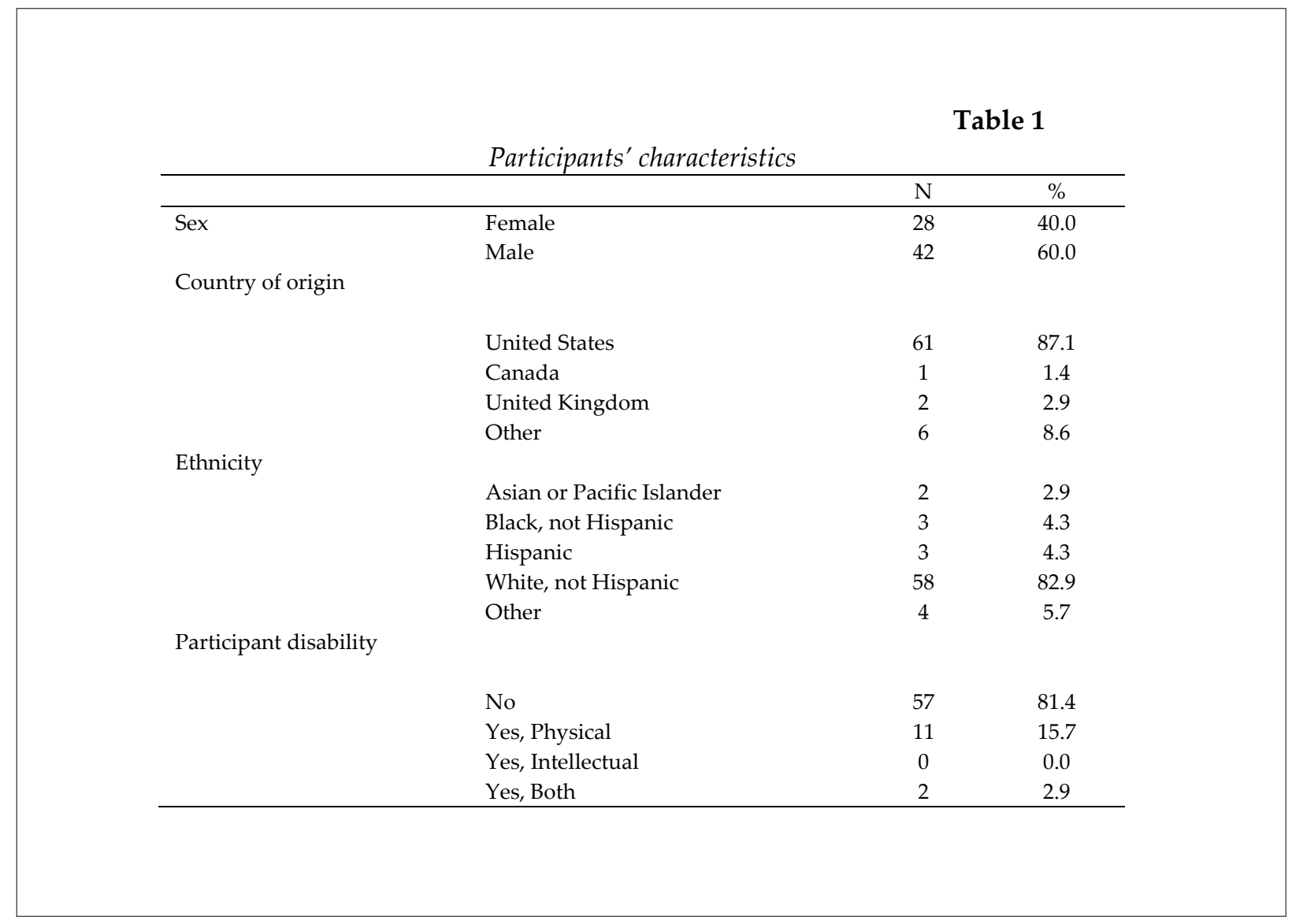


Table 2

Correlations of Coaching Efficacy, Sources, and Leadership Behaviors $(N=70)$

\begin{tabular}{|c|c|c|c|c|c|c|c|c|c|c|c|c|c|c|c|}
\hline & & 1 & 2 & 3 & 4 & 5 & 6 & 7 & 8 & 9 & 10 & 11 & 12 & 13 & 14 \\
\hline 1. & Coaching Efficacy & & & & & & & & & & & & & & \\
\hline 2. & Coaching Experience & $.30^{*}$ & - & & & & & & & & & & & & \\
\hline 3. & Playing Experience & $.32^{* *}$ & $.27^{*}$ & - & & & & & & & & & & & \\
\hline 4. & Prior Success & $-.50^{* *}$ & -.19 & -.17 & - & & & & & & & & & & \\
\hline 5. & Athlete Performance & $.47^{* *}$ & .14 & .07 & $-.33^{* *}$ & - & & & & & & & & & \\
\hline 6. & Athlete Improvement & $.55^{* *}$ & .12 & $.33^{* *}$ & $-.28^{*}$ & $.68^{* *}$ & - & & & & & & & & \\
\hline 7. & Athlete Support & $.32^{* *}$ & .05 & .07 & -.02 & $.43^{* *}$ & $.32^{* *}$ & - & & & & & & & \\
\hline 8. & Organization Support & $.24^{*}$ & .07 & .06 & -.09 & $.28^{*}$ & .23 & $.47^{* *}$ & - & & & & & & \\
\hline 9. & Community Support & $.26^{*}$ & .07 & .09 & -.04 & .13 & .20 & $.36^{* *}$ & $.60^{* *}$ & - & & & & & \\
\hline 10. & Instruction & $.68^{* *}$ & .14 & $.31^{* *}$ & $-.35^{* *}$ & $.24^{*}$ & $.40^{* *}$ & $.26^{*}$ & .14 & .14 & - & & & & \\
\hline 11. & Democratic & $.27^{*}$ & .18 & .14 & -.15 & .16 & .19 & .20 & .20 & $.26^{*}$ & $.26^{*}$ & - & & & \\
\hline 12. & Autocratic & -.10 & .15 & .03 & -.05 & -.01 & -.11 & -.12 & .01 & -.11 & -.08 & -.07 & - & & \\
\hline 13. & Social Support & .19 & -.18 & .01 & $-.28^{*}$ & .11 & .16 & .21 & .08 & .16 & .16 & .06 & .21 & - & \\
\hline 14. & Positive Feedback & $.41^{* *}$ & .06 & .05 & -.13 & .23 & .21 & .04 & .09 & .19 & $.29^{*}$ & .18 & -.17 & .16 & - \\
\hline
\end{tabular}

${ }^{*}$ Correlation is significant at the 0.05 level

** Correlation is significant at the 0.01 level

Table 3

Multiple Regressions for Coaching Efficacy Subscales Predicting Leadership Behaviors

\begin{tabular}{llll}
\hline DV & IV & B & $\beta$ \\
\hline Instruction & Motivation & .297 & .221 \\
& Game Strategy & .068 & .067 \\
& Character Building & -.016 & -.007 \\
& Teaching & .649 & $.469^{*}$ \\
Positive Feedback & Motivation & .073 & .160 \\
& Game Strategy & -.039 & -.113 \\
& Character Building & .168 & .223 \\
& & .115 & .245 \\
\hline
\end{tabular}

* Indicates significant differences 
Table 4

Multiple Regression for Sources of Coaching Efficacy Predicting Instructional Leadership

\begin{tabular}{llll}
\hline DV & IV & B & $\beta$ \\
\hline Instruction & Coaching Experience & .025 & .223 \\
Playing Experience & .150 & 1.229 \\
Prior Success & $-.289^{*}$ & -2.443 \\
Athlete Performance & -.180 & -1.076 \\
Athlete Improvement & .319 & 1.967 \\
Athlete Support & .227 & 1.704 \\
Organizational Support & -.034 & -.235 \\
Community Support & .013 & .095 \\
Total Coaching Efficacy & $.508^{*}$ & 5.110 \\
Coaching Experience & .010 & .080 \\
& Playing Experience & -.003 & -.021 \\
Prior Success & -.044 & -.329 \\
Athlete Performance & .213 & 1.125 \\
Athlete Improvement & .055 & .300 \\
Athlete Support & -.127 & -.778 \\
& Organizational Support & -.066 & -.403 \\
Community Support & .231 & 1.476 \\
Total Coaching Efficacy & $.508^{*}$ & 3.127 \\
& & \\
& & &
\end{tabular}

* Indicates significant differences at a .05 level.

\section{Sources of Coaching Efficacy that Predict Leadership Behaviors}

Hierarchical regression models were utilized to predict each of the significant leadership behavior categories from the previous research question (i.e., instruction and positive feedback) with respect to the sources of coaching efficacy (Table 4). Total coaching efficacy was determined to be a significant predictor of both instructional and positive feedback behavior. Prior success was also determined to be a significant predictor for instructional leadership behavior. In regard to positive feedback leadership behavior, the percent of variability accounted for by all sources of coaching efficacy $(22.4 \%)$ was significant, $F(9,60)=1.93, p<.05$, with total coaching efficacy as the only significant predictor.

\section{Discussion}

This study was designed to explore whether sources of coaching efficacy could predict leadership behaviors in coaches of AWPD, specifically current Paralympic coaches. Initial analyses also examined the relationship among the sources of coaching efficacy, perceived coaching efficacy, and leadership behaviors, as well as which subscales of coaching efficacy predicted certain leadership behaviors.

Pearson's correlations supported the relationship between total coaching efficacy andeach source of coaching efficacy. These results 
indicated that the Paralympic coaches reported higher levels of total coaching efficacy as they gained more coaching and playing experience, attained more success, became more competent in assisting their athletes to perform and improve, and received a greater amount of support from their athletes, organization, and community. Furthermore, the analyses supported relationships between total coaching efficacy and instructional and positive feedback leadership behaviors. These results are consistent with previous literature (Sullivan and Kent, 2003) and suggest that more efficacious coaches report using more training behaviors and teaching specific skills, as well as coordinating various activities alongside the display and use of praise and encouragement to improve athlete performance.

Coaching efficacy was also found to have a significant positive relationship with democratic behavior. This finding indicates that Paralympic coaches who allowed athletes greater participation in the decision-making process reported higher coaching efficacy. This is inconsistent with Sullivan and Kent's findings (2003), which indicated poor or inconsistent correlations between these variables. However, the present finding is supported by the selfdetermination theory (Deci and Ryan, 1985; Ryan and Deci, 2000), which describes that involving athletes in the decision-making process can address the psychological needs of autonomy within athletes. In other words, athletes who are provided opportunities to assist in the decisionmaking processes feel a greater sense of relatedness to the coach, autonomy over their own behavior, and competence to achieve their goals. The athletes' sense of relatedness, autonomy, and competence likely interact with one another, and, according to the selfdetermination theory, athletes high in all three are more intrinsically motivated to perform at the best of their ability, thereby potentially enhancing the coach's perception of his or her coaching ability.

The correlation analyses did not support the notion that there would be a positive relationship among each of the eight sources of coaching efficacy and instructional leadership behavior. However, there were significant correlations between five sources (i.e., playing experience, prior success, athlete performance, athlete improvement, and athlete support) and instruction. Paralympic coaches with a history of playing the sport coached, who had success enhancing their athletes' performance and development, and who had received reinforcement from their athletes, were shown to report higher levels of specific behaviors used to more effectively conduct training activities and teach the skills of the sport. Other sources linked to specific leadership behaviors are community support and democratic behavior, as well as athlete support and social support behavior. The relationships found in the present study for these four sources are not supported in previous literature; however, it is possible that democratic coaches receive a greater amount of community support because they are perceived as being more approachable due to their tendency to promote feedback from others, whereas autocratic coaches tend to act more independently and domineeringly.

For the main purpose of examining coaching efficacy dimensions that predict leadership behaviors, it was hypothesized that a) efficacy in motivation and character-building would predict social support and positive feedback; b) game strategy efficacy would predict democratic, autocratic, training, and instruction; c) technique efficacy would predict training and instruction; and d) coaches with high democratic coaching behaviors would be predicted by high amounts of coaching experience, playing experience, prior success, athlete improvement, and athlete support. Of the five models tested in the present study, the coaching efficacy dimensions as a group significantly predicted only instruction and positive feedback. Both models accounted for large amounts of variation in leadership behavior $(50 \%$ and $20 \%$ for instruction and positive feedback, respectively). In essence, Paralympic coaches who were efficacious as coaches engaged more often in instructional and positive feedback behaviors. Further analysis showed that technique efficacy predicted instructional leadership behavior, supporting the hypothesis. This relationship was the only subscale of coaching efficacy that predicted a specific leadership behavior. While the two variables seem synonymous, they are not mutually exclusive to one another. Instruction refers to the intent of improving athletes' 
performance through teaching and training activities, whereas technique efficacy refers to the level of confidence coaches have in providing technical instruction. Therefore, it is possible that Paralympic coaches who are less confident in their teaching ability rely more on basic instruction that is not athlete-specific, while Paralympic coaches who are more confident in their teaching ability provide more effective coaching which emphasizes more advanced athlete improvement.

For the two types of leadership behaviors which were analyzed, it was hypothesized that coaches who demonstrate greater positive feedback would derive their behavior from coaching experience, athlete performance, athlete improvement, and athlete support. For both positive feedback and instruction, total coaching efficacy was a significant predictor. However, prior success was the only source of coaching efficacy which was a significant predictor of a specific leadership behavior, i.e., instructional leadership. This result indicates that Paralympic coaches who successfully promote athlete enjoyment, skill and strategy, emotion management, and winning attitudes are likely to engage in instructional leadership behaviors to a greater extent than coaches who do not. On the contrary, Paralympic coaches who are not successful at promoting athlete enjoyment, skill and strategy, emotion management, and winning attitudes tend to engage less frequently in behaviors directed toward skill improvement activities (i.e., instructional leadership behaviors). Although the predictive relationship between technique efficacy and leadership behaviors has not been previously reported in the literature, it is intuitive that coaches are either more or less likely to demonstrate instructional behavior based on the amount of previous success attributed to them. This action by coaches could be due to the fact that athletes have been shown to respond more positively to instructional coaches since they make the sport more enjoyable, offer challenges with chances to be successful, and create opportunities to develop or refine new skills (Martin et al., 2001; Smoll and Smith, 1993). This finding suggests that the link between coaching efficacy sources and leadership are intertwined. There is not a specific skill set that will make a coach of athletes with disabilities a "good coach".
However, if the coach considers his/her experience enjoyable and important then it is likely that their efficacy as a coach will also improve. Thus, this relationship between coaching efficacy sources and leadership may increase the likelihood for the AWPD to have a positive experience within their chosen sport.

\section{Limitations}

There are some limitations with the present investigation that must be considered. The number of participants was relatively low, which could be partially due to the timing of this study as it was conducted in the winter and spring prior to the summer Paralympic Games. Additionally, the sources of coaching efficacy evaluated in this study were based solely on the various sources identified as part of the coaching efficacy model (Feltz et al., 1999). Therefore, no coaching efficacy sources unique to sport coaches working with AWPD were identified. Furthermore, the CSQ-2 was developed for use with athletes, but was further modified for use with coaches in this study. In revising this questionnaire, the sentence structure may have been confusing for the participant, as the word "you", for example, remained in the question and may have been ambiguous to the reader (e.g., "I teach you that winning is the most important reason for competing"). Also, some of the reworded statements could have been highly subjected to self-serving bias and social desirability (e.g., "I teach the important strategies of sport"). Additionally, there was no data collected to show the duration of the relationship between coaches and their athletes. This omission poses difficulty in analyzing athlete past improvement. Lastly, the use of single items to measure was not ideal as they could not be evaluated for internal consistency and may have failed to accurately measure the respective variable.

\section{Implications and Future Directions}

Significant results of this exploratory study provide several implications for sports organizations and coaching education programs. Knowing that each source of coaching efficacy is correlated with the total coaching efficacy level, sport education courses for AWPD should emphasize the importance of each source of coaching efficacy. Moreover, organizations searching to find leaders who demonstrate more 
instructional and positive reinforcement behaviors should seek to at least consider, if not employ higher efficacious coaches or include programming to develop efficacy in coaches. The BlazeSports Institute was founded in 2003 with the goal of improving knowledge and increasing the amount of inclusive programs. BlazeSports continues to hold webinars and education training for those who want to work in adaptive sports with AWPD. The expansion and awareness of such programs needs to develop further to ensure coaches receive sport education.

Future studies should extend to other populations of coaches (e.g., university and high school coaches of AWPD) in order to gather results more generalizable while providing specific information to the sport level. Longitudinal studies would also assist in further evaluating the oscillation of coaching efficacy, its sources, and leadership behavior changes over time to better capture the true effect of the interactions between coaches, athletes, and teams as well as providing value to determine if there are unique sources of efficacy development for coaches of AWPD.

\section{Acknowledgements}

Ball State University, School of Kinesiology, 2000 W. University Ave., Muncie, IN 47306; Sanford Sports Science Institute, 2215 W Pentagon Place, Sioux Falls, South Dakota, 57107; Western Michigan University, 1903 W Michigan Avenue, Kalamazoo, MI, 49008; University of North Carolina at Charlotte, 9201 University City Boulevard, Charlotte, NC, 28223

\section{References}

Bandura A. Social foundations of thought and action: A social cognitive theory. Englewood Cliffs: Prentice Hall, 1986

Bennie A, O'Conner D. Coaching philosophies: Perceptions from professional cricket, rugby league and rugby union players and coaches in Australia. Int J Sports Sci Coa, 2010; 5(2): 309-320

Castagno KS. Special olympics unified sports: Changes in male athletes during a basketball season. Adapt Phys Act Q, 2001; 18(2): 193-206

Chelladurai P. Human resource management in sport and recreation. Champaign: Human Kinetics; 1999

Chelladurai P. Leadership in sports. Handbook of Sport Psychology, Third Edition Hoboken: John Wiley \& Sons, Inc., 115-130; 2007

Chelladurai P, Saleh SD. Preferred leadership in sports. Can J Appl Sport Sci, 1978; 3: 85-92

Chelladurai P, Saleh SD. Dimensions of leader behavior in sports: Development of a leadership scale. Int $J$ Sport Psychol, 1980; 2: 34-45

Deci EL, Ryan RM. Intrinsic motivation and self-determination in human behavior. Plenum: Springer; 1985

Feltz DL, Chase MA, Moritz SE, Sullivan PJ. A conceptual model of coaching efficacy: Preliminary investigation and instrument development. Jpn J Educ Psychol, 1999; 91(4): 765-776

Gibbons SL, Bushakra FB. Effects of special olympics participation on the perceived competence and social acceptance of mentally retarded children, Adapt Phys Act Q, 1989; 6(1): 40-51

Gillham A, Burton D, Gillham E. Going beyond won-loss record in sdentifying successful coaches: Development of the coaching success questionnaire-2. Int J Sports Sci Coa, 2013; 8(1): 115-138

Gillham A, Gillham E, Hansen K. Relationships among coaching success, servant leadership, cohesion, resilience and social behaviors. Int Sport Coach J, 2015; 2(3): 233-2

Greenleaf RK. Servant leadership: A journey into the nature of legitimate power and greatness. Mahwah: Paulist Press; 1977

Harada CM, Siperstein GN. The sport experience of athletes with intellectual disabilities: A national survey of special olympics athletes and their families. Adapt Phys Act Q, 2009; 26(1): 68-85 
Kent A, Sullivan PJ. Coaching efficacy as a predictor of university coaches' commitment. Int Sports J, 2003; 7(1): 78-87

Macdougall H, O'Halloran P, Sherry E, Shields N. Needs and strengths of Australian para-athletes: Identifying their subjective psychological, social, and physical health and well-being. Sport Psychol, 2016; 30(1): 1-12

Macdougall H, O'Halloran P, Shields N, Sherry E. (2015). Comparing the well-being of Para and Olympic sport athletes: A systematic review. Adapt Phys Act Q, 2015; 32(3): 256-276

Machek MA, Stopka CB, Tillman MD, Sneed SM, Naugle KE. The effects of a supervised resistance-training program on special olympics athletes. J Sport Rehabil, 2008; 17(4): 372-379

Martin SB, Dale GA, Jackson AW Youth coaching preferences of adolescent athletes and their parents. J Sport Behav, 2001; 24(2): 196-215

Myers ND, Wolfe EW, Feltz DL. An evaluation of the psychometric properties of the coaching efficacy scale for coaches from the United States of America. Meas Phys Educ Exerc Sci, 2005; 9(3): 135-161

Rieke M, Hammermeister J, Chase M. Servant leadership in Sport: A new paradigm for effective coach behavior. Int J Sports Sci Coa, 2008; 3(2): 227-239

Robbins JE, Houston E, Dummer GM. Philosophies and expectations of wheelchair and stand-up collegiate basketball coaches. Int J Sports Sci Coa, 2010; 33(1): 42-62

Ryan RM, Deci EL. Intrinsic and extrinsic motivations: classic definitions and new directions. Contemp Educ Psychol, 2000; 25(1): 54-67

Seltzer J, Bass BM. Transformational leadership: Beyond initiation and consideration. J Manage, 1990; 16(4): 693-703

Smoll FL, Smith RE. Educating youth sport coaches: An applied sport psychology perspective. Applied Sport Psychology: Personal Growth to Peak Performance (2nd ed.), Mayfield: McGraw Hill, 36 - 57; 1993

Sullivan PJ, Kent A. Coaching efficacy as a predictor of leadership style in intercollegiate athletics. J Appl Sport Psychol, 2003; 15(1): 1-11

Vargas-Tonsing TM, Warners AL, Feltz DL. The predictability of coaching efficacy on team efficacy and athlete efficacy in volleyball. J Sport Behav, 2003; 26(4): 396-406

Walach-Bista Z. Leadership scale for sports - theoretical background and review of psychometric properties research. Čes. Kinantropologie, 2014; 18(3): 67-76

Wang J, Straub W. An investigation into the coaching approach of a successful world class soccer coach: Anson Dorrance, Int J Sports Sci Coa, 2012; 7(3): 431-448

\section{Corresponding author:}

\section{Dr. Lawrence W. Judge}

Professor - School of Kinesiology

Ball State University - HP 360M

Muncie, IN 47306

Phone: (765) 285-4211

Fax: (765) 285-8254

E-mail address: lwjudge@bsu.edu 